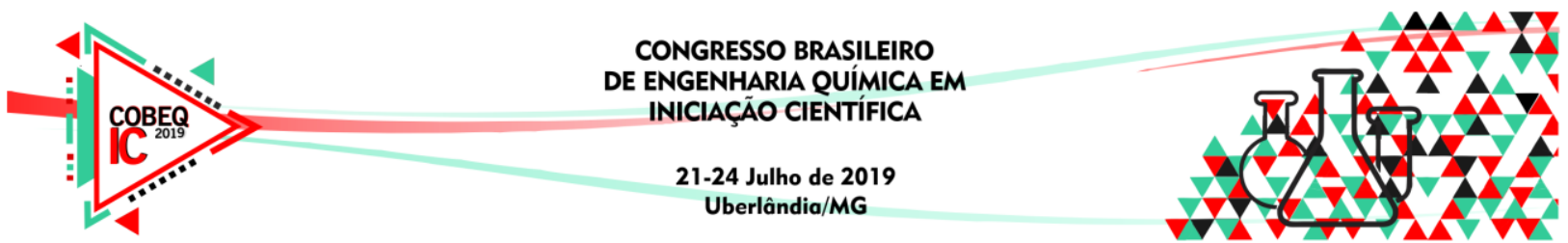

\title{
PROSPECÇÃO QUíMICA DO EXTRATO ALCOÓLICO DAS FOLHAS DE Antonia ovata Pohl (Loganiaceae) E AVALIAÇÃO DO SEU EFEITO CARCINOGÊNICO EM CÉLULAS SOMÁTICAS DE Drosophila melanogaster
}

\author{
R. C. R. PEREIRA ${ }^{1}$, M. P. O. RAMOS ${ }^{2}$ e M. A. VASCONCELOS ${ }^{3}$ \\ ${ }^{1}$ Graduando em Engenharia Química - Centro Universitário de Patos de Minas \\ ${ }^{2}$ Professora orientadora - docente no Centro Universitário de Patos de Minas \\ ${ }^{3}$ Professora coorientadora - docente no Centro Universitário de Patos de Minas \\ E-mail para contato: contatoraphaelpereira@ gmail.com
}

\begin{abstract}
RESUMO - Antonia ovata pohl (Loganiaceae) é uma espécie encontrada no Cerrado brasileiro, sendo relevante devido a sua ação ictiotóxica. Objetiva-se avaliar a carcinogenicidade do extrato alcoólico das folhas da A. ovata em células somáticas de Drosophila melanogaster e fazer a sua prospecção química. Realizou-se o teste WTS em D. melanogaster provenientes do cruzamento de fêmeas WTS/TM3 com machos $M W H / M W H$, tratadas com os controles negativo (etanol - 5\%), positivo (Doxorrubicina - $4 \mathrm{mM}$ ) e concentrações do extrato $(0,625$; 1,25 e $2,5 \mathrm{mg} / \mathrm{ml}$ ). A prospecção seguiu as metodologias: saponinas (espumaagitação), flavonoides (fita de $\mathrm{Mg}$ ), taninos $\left(\mathrm{FeCl}_{3}\right)$, cumarinas (UV), triterpenos e esteroides (Liebermann-Burchard). Constata-se que não houve diferenças significativas na frequência de tumores nas concentrações utilizadas, além da presença de flavonoides, saponinas, cumarinas, esteroides e taninos. Nas presentes condições, o extrato etanólico de $A$. ovata não induz formação de tumores em $D$. melanogaster devido à ação antioxidante dos flavonoides e taninos presentes.
\end{abstract}

\section{INTRODUÇÃO}

Devido à sua grande biodiversidade, a flora brasileira é considerada uma das mais ricas do mundo, com mais de 56.000 espécies, sendo 4.756 de Algas, 33.297 de Angiospermas, 1.571 de Briófitas, 5.719 de fungos, 29 de gimnospermas e 1361 de Samambaias e Licófitas. (FORZZA, 2019). Sabe-se que as plantas da família Loganiaceae são conhecidas pelo seu conteúdo de alcaloides e iridoides. Além disso, há apenas um representante dessa família que apresenta saponinas em seu conteúdo, o gênero denominado Antonia ovata Pohl. (MAGID et al., 2010).

De acordo com Luitgards-Moura et al., (2002), essa espécie é muito utilizada por comunidades indígenas na região de Roraima para a pesca, devido ação ictiotóxica nos peixes e seu estudo também comprova a ação inseticida da planta em Lutzomyia longipalpis.

Desta forma, analisando as propriedades deste vegetal e sua fácil aquisição, é relevante pesquisar o seu possível efeito carcinogênico em diferentes organismos modelos. Sendo assim, este trabalho objetiva avaliar o efeito carcinogênico do extrato alcoólico das folhas de A. ovata por meio do teste para detecção de clones de tumores epiteliais (WARTS) em células 


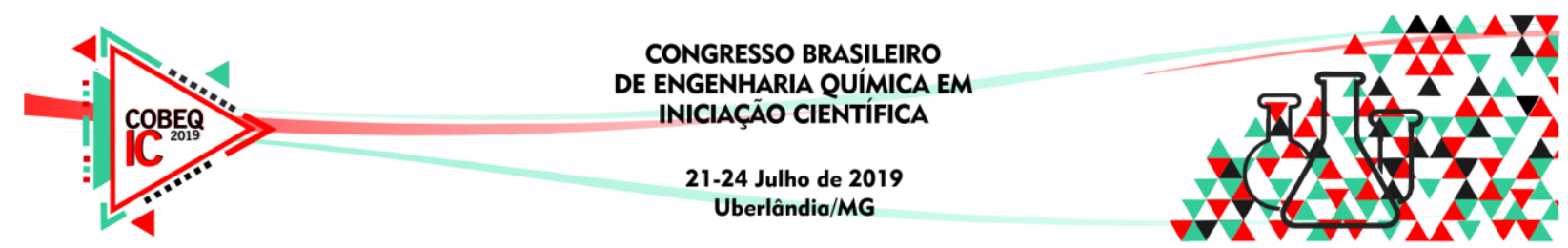

somáticas de Drosophila melanogaster, determinando as principais classes de metabólitos presentes na planta.

\section{REVISÃO DA LITERATURA}

\subsection{Antonia ovata Pohl}

Proveniente da família Loganiaceae, o gênero Antonia possui diversas espécies, mas é a Antonia ovata Pohl uma das mais popularmente encontradas no Brasil, no Cerrado e nas Savanas de Roraima, onde é encontrada na forma de arbusto, de acordo com o estudo de Miranda e Absy (2000). Segundo estudo de Luitgards-Moura et al. (2002), Antonia ovata Pohl faz parte de um grupo de plantas conhecidas pelo seu efeito ictiotóxico, genericamente denominado de timbó. A utilização de plantas com essa propriedade é muito comum nas tribos indígenas da Amazônia, para fins pesqueiros. Seu uso, de acordo com Magid et al. (2010) é devido à presença saponinas em sua composição, metabólito que teve comprovação de seu efeito tóxico em peixes no estudo de Tabarelli e Bonoldi (1945).

\subsection{Drosophila melanogaster}

Drosophila melanogaster tem sido utilizada intensivamente para pesquisas de mutação e em testes de curto prazo para identificar carcinógenos. (Vogel et al., 1999). Nepomuceno (2015) caracteriza a D. melanogaster como um modelo bem estabelecido para estudo genético pois tem uma geração curta de 10 dias a $25^{\circ} \mathrm{C}$, seu caráter morfológico tem sido facilmente detectável, possui grande número de mutantes e variedades genéticas, os meios de cultura são baratos e simples e é capaz de ativar efeitos de mutação e carcinogênese in vivo.

\section{MATERIAIS E MÉTODOS}

\subsection{Coleta e Obtenção do Extrato das Folhas de Antonia ovata Pohl}

O material vegetal foi coletado na região de Tabocas - MG em março de 2018, sendo posteriormente submetido à secagem em estufa de ar circulante a uma temperatura de $40^{\circ} \mathrm{C}$ por 48 horas até desidratação. A seguir o material foi triturado e submetido à extração com etanol absoluto por percolação durante alguns dias. Após isso, realizou-se a filtração do percolado e o etanol reduzido foi recuperado em rotaevaporador, obtendo-se o extrato etanólico de A. ovata.

\subsection{WARTS (WTS) - Teste Para Detecção de Clones de Tumor Epitelial em Drosophila melanogaster}

Para realização do teste WTS (WARTS) foram utilizadas duas linhagens mutantes de $D$. melanogaster (WTS e MWH) portadoras dos marcadores genéticos WARTS (WTS, 3-100) e multiple wing hairs, (3-03). O meio de cultura é composto por $820 \mathrm{~mL}$ de água, $25 \mathrm{~g}$ de fermento (Sacchoromyces cerevisae), $11 \mathrm{~g}$ de ágar, $156 \mathrm{~g}$ de banana e $1 \mathrm{~g}$ de nipagin. Foram utilizadas larvas heterozigotas de 72 horas $W T S+/+M W H$ tratadas com soluções de $5 \mathrm{~mL}$ do extrato nas concentrações de $2,5 \mathrm{mg} / \mathrm{mL}, 1,25 \mathrm{mg} / \mathrm{mL}$ e $0,625 \mathrm{mg} / \mathrm{mL}$. 


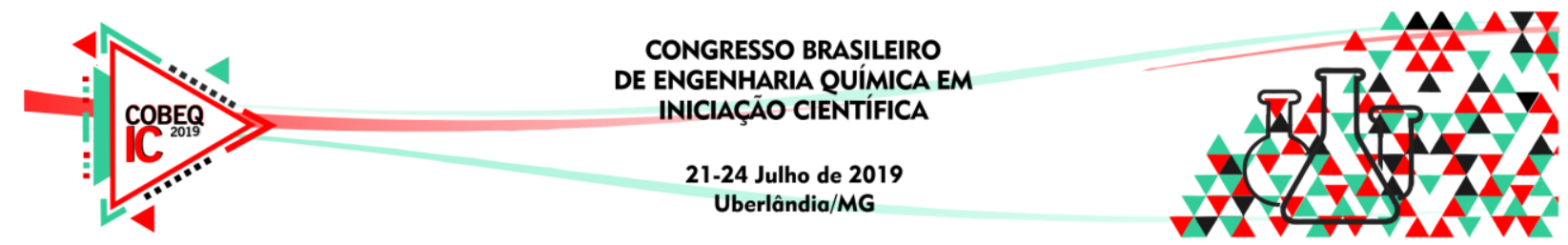

Após o tratamento, as moscas adultas de pêlo longo foram analisadas para visualização e contagem da presença de tumores. As diferenças estatísticas entre as frequências de tumores das concentrações testadas e os controles, foram calculadas utilizando o teste $U$, não paramétrico, de Mann-Whitney, empregando o nível de significância $\alpha=0,05$. Em todos os experimentos foram utilizados $25 \mathrm{ml}$ de água de osmose reversa como solvente para diluir $0,03538 \mathrm{~g}$ de cloridrato de doxorrubicina, resultando em uma concentração de $0,4 \mathrm{mM}$, sendo a DXR o controle positivo.

\subsection{Caracterização química para identificação de metabólitos especiais}

Os ensaios químicos para avaliar a presença de saponinas (espuma-agitação), flavonoides (reação com fita de magnésio), taninos (reação com cloreto férrico), cumarinas (observação sob UV) e triterpenos e esteroides (reação de Liebermann-Burchard) seguiram os métodos convencionais descritos por Nunes e Ribeiro (2017) e Pereira et al. (2017) por mudança de cor e/ou formação de precipitados.

\section{RESULTADOS E DISCUSSÕES}

\subsection{WARTS (WTS) - Teste para Detecção de Clones de Tumor Epitelial em Drosophila melanogaster}

Foi realizado teste de toxicidade do extrato das folhas de $A$. ovata nas concentrações de 0,$625 ; 1,25$ e $2,5 \mathrm{mg} / \mathrm{mL}$. A Figura 1 mostra que a taxa de mortalidade não foi superior à 15 \%; desta forma, confirmando não toxicidade e assegurando a utilização destas concentrações.

Figura 1 - Taxas de mortalidade e sobrevivência de D. melanogaster expostas ao controle negativo (Etanol 5\%), ao controle positivo (Doxorrubicina)

e concentrações de E.E.A.o $(0,625 ; 1,25$ e $2,5 \mathrm{mg} / \mathrm{ml})$

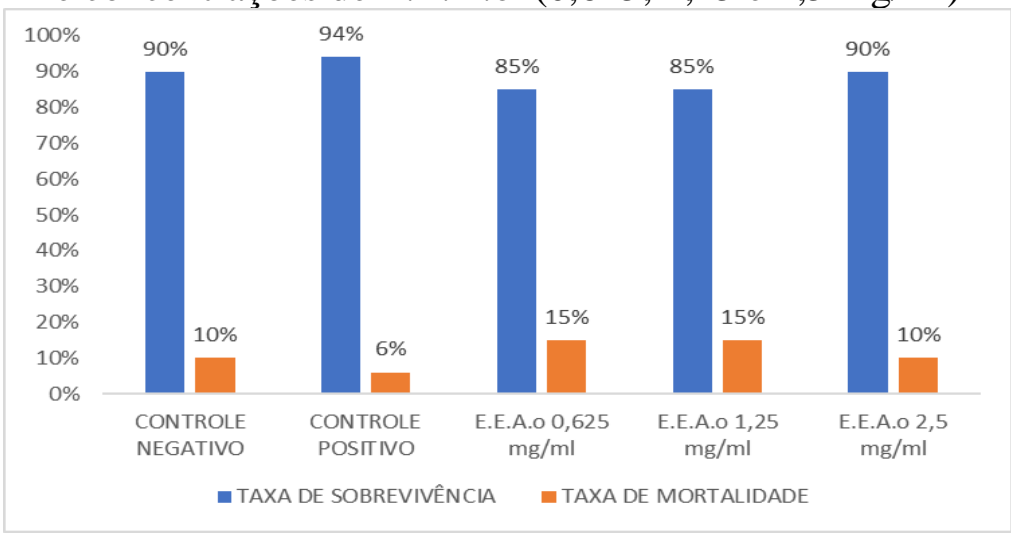

Fonte: Dados da pesquisa, 2019.

Após a coleta das $D$. melanogaster sobreviventes e contagem para análise dos tumores epiteliais, foi elaborada a Tabela 1, que apresenta a frequência de tumores em cada parte do organismo analisada: olhos, cabeça, corpo, asas, pernas e halteres, além do total de tumores encontrados no controle positivo de Doxorrubicina (DXR - 0,4 mM) e negativo de Etanol $5 \%$. 


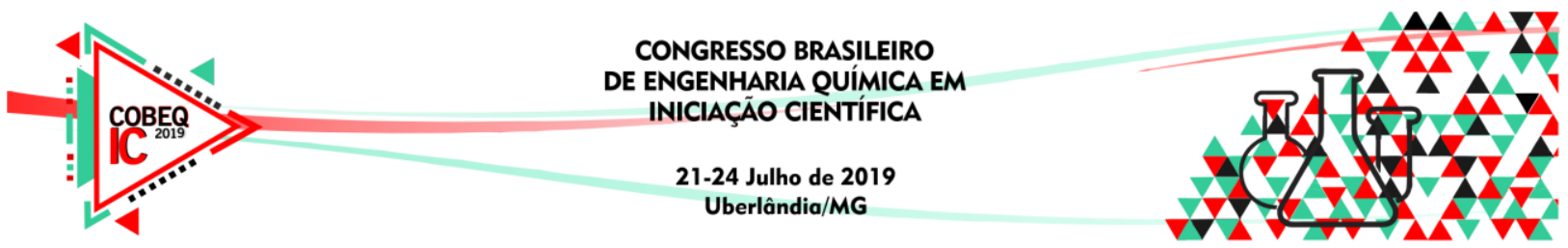

Tabela 1 - Frequência do clones tumores epiteliais observada em D. melanogaster, heterozigoto para o gene supressor de tumor WTS, tratadas isoladamente com os controles negativo (Etanol 5\%), positivo (DXR 0,4mM) e concentrações do Extrato Etanólico de $A$. ovata $(0,625 ; 1,25$ e $2,5 \mathrm{mg} / \mathrm{ml})$

\begin{tabular}{|c|c|c|c|c|c|c|c|c|c|c|c|}
\hline \multicolumn{3}{|c|}{ Tratamentos } & \multirow[b]{2}{*}{$\begin{array}{l}N^{0} \text { de } \\
\text { moscas }\end{array}$} & \multicolumn{6}{|c|}{ Número de tumores analisados } & \multirow[b]{2}{*}{ Total } & \multirow[b]{2}{*}{$\begin{array}{c}\text { Frequência } \\
\left(\mathrm{N}^{\mathbf{o}} \text { de tumores/mosca }\right)\end{array}$} \\
\hline $\begin{array}{l}\text { E.E.A.o } \\
(\mathbf{m g} / \mathbf{m l})\end{array}$ & $\begin{array}{l}\text { DXR } \\
(\mathbf{m M})\end{array}$ & $\begin{array}{c}\text { Etanol } \\
(\%)\end{array}$ & & Olho & Cabeça & Asa & Corpo & Perna & Halter & & \\
\hline 0 & 0 & 5 & 150 & 15 & 7 & 46 & 65 & 20 & 6 & 158 & $1,06(158)$ \\
\hline 0 & 0,4 & 0 & 150 & 20 & 165 & 745 & 375 & 286 & 80 & 1664 & $11,14(1664)^{*}$ \\
\hline 0,625 & 0 & 0 & 150 & 25 & 6 & 52 & 86 & 23 & 14 & 204 & $1,37(204)$ \\
\hline 1,25 & 0 & 0 & 150 & 9 & 20 & 66 & 73 & 26 & 16 & 208 & $1,58(208)$ \\
\hline 2,5 & 0 & 0 & 150 & 14 & 9 & 50 & 113 & 14 & 14 & 212 & $1,43(212)$ \\
\hline
\end{tabular}

Diagnóstico estatístico de acordo com o teste de Mann-Whitney. Nível de significância $p \leq 0,05$.

$*$ Valor considerado diferente do controle negativo $(p<0,05)$.

Fonte: Elaborado pelo autor, 2019.

A Tabela 1 mostra que houve diferenças significativas na frequência de tumores encontrada no controle positivo (DXR - 0,4 mM) se comparada ao negativo, o que se comprova pelo mecanismo de ação da Doxorrubicina, que segundo Kaiserová et al. (2006), induz o estresse oxidativo, formando espécies reativas de oxigênio, que causam danos a células cardíacas e neoplásicas, devido à fraca defesa antioxidante que as células possuem.

Sendo assim, a Tabela 1 mostra que o teste para detecção de tumores foi eficiente para identificar que não há potencial carcinogênico, pois não houve alteração significativa em relação ao número de tumores encontrados nas concentrações de 2,5; 1,25; e 0,625 mg/ml.

Portanto, verificou-se a necessidade de realizar testes de prospecção química do extrato, para a identificação de compostos que possam ter contribuído com a ausência de atividade carcinogênica.

\subsection{Identificação de Metabólitos Especiais}

Com base nos testes de identificação de metabólitos especiais, foi elaborada a Tabela 2, que apresenta os resultados obtidos nos testes para evidenciar a presença desses metabólitos, bem como as evidências de resultado positivo.

Tabela 2 - Metabólitos especiais nas folhas de Antonia ovata Pohl

\begin{tabular}{llll}
\hline Metabólito & Teste & Evidência & Resultado \\
\hline Flavonoides & Shinoda & Mudança de cor (avermelhada) & ++ \\
Cumarinas & NaOH 10\% & Fluorescência em luz UV $(\lambda \sim 365 \mathrm{~nm})$ & + \\
Cumarinas & $\mathrm{KOH}$ e Metanol & Fluorescência em luz UV $(\lambda \sim 365 \mathrm{~nm})$ & + \\
Triterpenos & Liebermann-Burchard & Mudança de cor (vermelho $\rightarrow$ marrom) & - \\
Esteroides & $\mathrm{Liebermann-Burchard}$ & Mudança de cor (verde $\rightarrow$ azul) & ++ \\
Taninos hidrolisáveis & $\mathrm{Cu}\left(\mathrm{CH}_{3} \mathrm{COO}\right)_{2} 10 \%$ & Precipitado esbranquiçado & - \\
Taninos hidrolisáveis & $\mathrm{FeCl}{ }_{3} 2 \%$ & Mudança de cor (azul) & - \\
Taninos condensados & $\mathrm{FeCl}_{3} 2 \%$ & Mudança de coloração (verde) & ++ \\
Saponinas & $\mathrm{Teste} \mathrm{de} \mathrm{espuma}^{2}$ & Formação de espuma & ++ \\
\hline
\end{tabular}

Fonte: Elaborado pelo autor, 2019. 


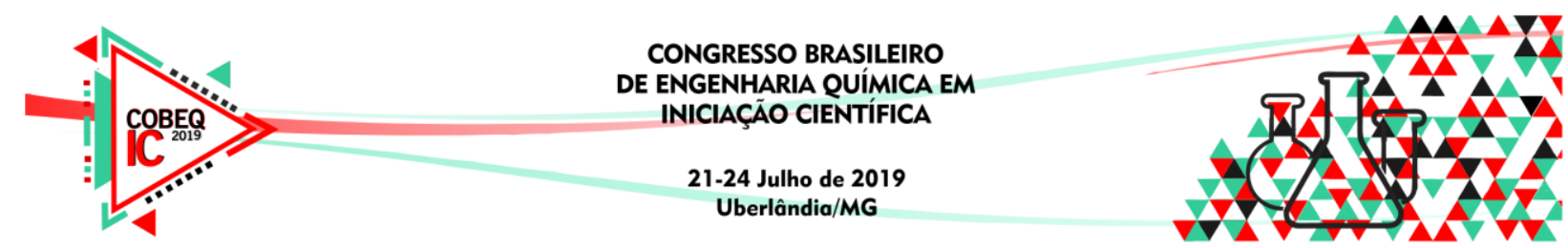

Tendo em vista os resultados apresentados na Tabela 2, as folhas de Antonia ovata Pohl possuem flavonoides, cumarinas, esteroides, taninos condensados e saponinas. Nesse sentido, a presença de cumarinas, de acordo com Ruivo (2012), permite aplicações da planta na fitoquímica devido à sua atuação como antioxidante, inibição de agregação plaquetária e antiinflamatória. Já os esteroides, segundo Queiroz (2009), podem ser aplicados no controle de colesterol, como método anticoncepcional e além de aplicações na cosmética e nutrição.

Segundo Ruivo (2012), os flavonoides são importantes para o aumento da resistência capilar, além de possuírem propriedades antioxidantes, calmantes, desenvolvendo ação antiinflamatória e atuam como agentes antienvelhecimento na cosmética. Além disso, conforme Castejon (2011), os taninos estão sendo atribuídos a atividades antibacterianas, reparação de tecidos e cicatrização de feridas, estimulação de células fagocíticas, e ação antioxidante.

Machado et al. (2008) relacionam as moléculas de radicais livres à ocorrência de tumores, fato que pode ser comprovado devido a capacidade destas moléculas atacarem as biomoléculas como o DNA. Neste contexto, os antioxidantes por serem compostos que podem retardar ou inibir a oxidação de biomoléculas, como o DNA, evitam o início ou propagação das reações de oxidação em cadeia (DEGÁSPARI; WASZCZYNSKYJ, 2004) e a ocorrência de divisões celulares descontroladas, responsáveis pelos tumores.

Tendo em vista a presença significativa de flavonoides e taninos, sugere-se que esses metabólitos foram os mais impactantes nos resultados do Teste WTS em Drosophila melanogaster, devido a sua comprovada atuação antioxidante (DEGÁSPARI; WASZCZYNSKYJ, 2004; PESSUTO et al. 2009).

\section{CONCLUSÃO}

A presença de flavonoides, saponinas, cumarinas, esteroides e taninos ns folhas de Antonia ovata Pohl torna o vegetal utilizável na indústria farmacêutica na aplicação em medicamentos e em produtos cosméticos.

No teste WTS em Drosophila melanogaster, não foi constatada atividade carcinogênica quando aplicadas as concentrações de 0,$625 ; 1,25$ e $2,5 \mathrm{mg} / \mathrm{mL}$ do extrato, fato este que pode estar relacionado à presença dos flavonoides e taninos encontrados em maior quantidade no extrato da planta.

São sugeridas pesquisas futuras em relação à atividade anticarcinogênica do extrato, com aplicação em organismos de forma associada a Doxorrubicina (DXR - 0,4 mM).

\section{REFERÊNCIAS}

CASTEJON, F.V. Taninos e Saponinas. 2011. 29 f. Dissertação (Mestrado) - Curso de Ciência Animal, Escola de Veterinária e Zootecnia, Universidade Federal de Goiás, Goiânia, 2011.

DEGÁSPARI, C. H.; WASZCZYNSKYJ, N. Propriedades antioxidantes de compostos fenólicos. Visão Acadêmica. v. 5, n. 1, p. 33-40, 2004.

FORZZA, R. C. Flora do Brasil 2020 em construção. Jardim Botânico do Rio de Janeiro. Disponível em: <http://floradobrasil.jbrj.gov.br/>. Acesso em: 1 mar. 2019.

KAISEROVÁ, H.; HARTOG, G. J. M. den; SIMUNEK, T.; SCHRÖTEROVÁ, L.; KVASNICKOVA, E.; BAST, A. Iron is not involved in oxidative stress-mediated 


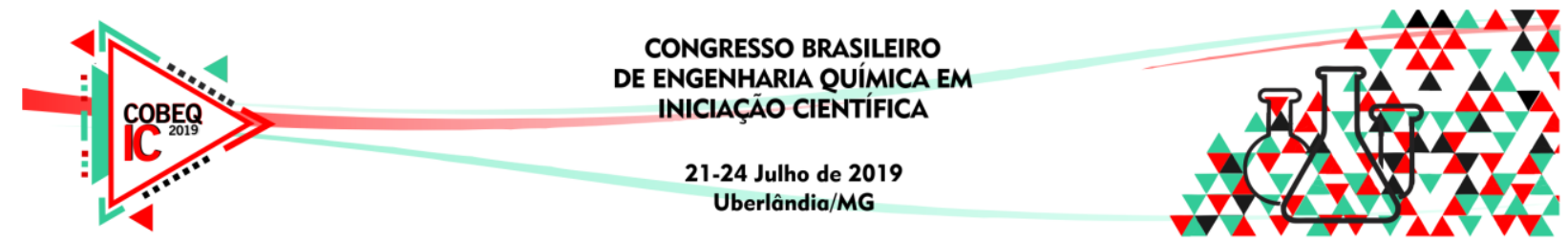

cytotoxicity of doxorubicin and bleomycin. British Journal Of Pharmacology. p. 920930, 2006.

LUITGARDS-MOURA, J.F., BERMUDEZ, E. G. C., ROCHA, A. F. I. da; TSOURIS, P., ROSA-FREITAS, M.G. Preliminary assays indicate that Antonia ovata (Loganiaceae) and Derris amazonica (Papilionaceae), ichthyotoxic plants used for fishing in Roraima, Brazil, have an insecticide effect on Lutzomyia longipalpis (Diptera: Psychodidae: Phlebotominae). Memórias do Instituto Oswaldo Cruz, v.97, p.737-742, 2002.

MACHADO, H.; NAGEM, T. J.; PETERS, V. M.; FONSECA, C. S.; OLIVEIRA, T. T. Flavonóides e seu potencial terapêutico. Boletim do Centro de Biologia da Reprodução, Juiz de Fora, v. 27, n. 1/2, p. 33-39, 2008.

MAGID, A., BOBICHON, H., LALUN, N., LONG, C., MORETTI, C., LAVAUD, C., Cytotoxic triterpenoid saponins from the stem bark of Antonia ovata. Phytochemistry. v. 71, p. 429-434, 2010.

MIRANDA, I. S.; ABSY, M. L. Fisionomia das savanas de Roraima, Brasil. Acta Amazônica, Manaus, v. 3, n. 30, p.423-440, 2000.

NEPOMUCENO, J. C. Using the Drosophila melanogaster to Assessment Carcinogenic Agents through the Test for Detection of Epithelial Tumor Clones (WARTS). Advanced Techniques In da Biology \& Medicine. v.3, 149 p. 2015.

NUNES, R. F.; RIBEIRO, K. P.; Identificação de metabólitos secundários e determinação de antocianinas e flavonoides totais em sementes de Bixa orellana L. (Urucum). In: XXII Jornada em Engenharia Química. Anais. Uberlândia: Peteq, 2017. p. 107 - 110.

PEREIRA, R. C. R. et al. Produção de pomada cicatrizante à base do extrato glicólico de cladódios da Pitaia Vermelha (Hylocereus undatus). In: XXII Jornada em Engenharia Química. Anais. Uberlândia: Peteq, 2017. p. 320 - 326.

PESSUTO, M. B. et al. Atividade antioxidante de extratos e taninos condensados das folhas de Maytenus ilicifolia Mart. ex Reiss. Química Nova, São Paulo, v. 32, n. 2, p.412-416, 26 jan. 2009.

QUEIROZ, G. S. Análise de Esteroides em Extratos Vegetais e Estudo Fitoquímico e Biológico Preliminar de Brunfelsia uniflora. Relatório de Estágio - Curso de Química, Departamento de Química, Ufsc, Florianópolis, 56 f., 2009.

RUIVO, J. S. P. Fitocosmética: aplicação de extratos vegetais em cosmética e dermatologia. Mestrado - Curso de Ciências Farmacêuticas, Faculdade de Ciências da Saúde, Universidade Fernando Pessoa, Porto, 96 f., 2012.

TABARELLI, N. J. F.; BONOLDI, V. Da ação da saponina sobre peixes: Guarus (Poecilia sp.) e Acarás (Geophagus sp.). Revista da Faculdade de Medicina Veterinária, v. 3, n. 1, p.19-26, dez. 1945.

VOGEL, E. W.; GRAF, U.; FREI, H. J.; NIVARD, M. M. The results of assays in Drosophila as indicators of exposure to carcinogens. IARC Sci Publ 146: 427- 470, 1999. 